\title{
Acute gastroenteritis in well nourished infants: comparison of four feeding regimens
}

\author{
S P CONWAY* AND A IRESON† \\ Departments of ${ }^{*}$ Infectious Disease and †Dietetics, Seacroft Hospital, Leeds
}

SUMmary Two hundred well hydrated babies of 6 weeks to 12 months of age who had been fed on formula feeds and who were admitted with acute gastroenteritis were randomly allocated to receive either a standard return to full milk feeds, or immediate full strength feeds with one of three milk formulas, HN25, SMA Gold Cap, or Formula S. There were significant differences in weight change among the four treatment groups at two and five days, with initial weight loss recorded only for the group of babies who were receiving the graded return to full feeding. There was no difference in the duration of diarrhoea after admission, nor in the time to discharge. Eighteen babies were classified as failures of treatment. None had long term complications. Well hydrated infants with acute gastroenteritis may resume full milk feeding immediately.

Acute gastroenteritis is an important cause of morbidity among infants in Britain. ${ }^{12}$ Optimum nutritional management of these children is controversial. ${ }^{3}$ In 1948 Chung showed better weight gain, larger and more solid stools, effective absorption of all food elements, and no increase in the duration of diarrhoea in infants with acute gastroenteritis treated with early full feeding. ${ }^{4}$ Malnourished children with repeated attacks of acute gastroenteritis may enter a cycle of protein energy/ fluid electrolyte malnutrition induced by periods of enforced starvation during treatment. Early rapid and full refeeding can interrupt this cycle without causing any deterioration in the diarrhoeal illness, ${ }^{6}$ by preventing the fall in intestinal mucosal disaccharidase activity associated with fasting ${ }^{7}$ and potentially helping to maintain the integrity of the intestinal mucosa. ${ }^{3}$ None the less, many well nourished, well hydrated infants in the developed world are still fed on oral glucose electrolyte solutions for at least the first 24 to 48 hours of their diarrhoeal illness. Formula milks and other foods are then introduced gradually over periods of two to five days. A more rapid return to full feeds for older children is now recommended by some, but caution is still advised for infants less than 6 months old. ${ }^{9}$

Theoretically delayed feeding may avoid the complications of carbohydrate malabsorption, of increased fluid loss and systemic acidosis, and of food intolerance resulting from the absorption of whole protein by the damaged mucosa. ${ }^{3}$ In practice the incidence of carbohydrate malabsorption associated with acute infantile gastroenteritis has been falling since the introduction of low solute formula feeds. ${ }^{10}$ These are as effective as hypoallergenic formulas in preventing sensitisation to cows' milk protein. ${ }^{11}$

The purpose of this study was to compare rapid refeeding with either a standard cows' milk formula feed (SMA Gold Cap), a low lactose formula (HN25), or a soya based milk (Formula S) with a period of fasting followed by a gradual reintroduction of full strength feeds, in the treatment of acute gastroenteritis in well nourished infants.

\section{Patients and methods}

Two hundred consecutive babies aged 6 weeks to 12 months, who had been fed on formula feeds and who were admitted with acute gastroenteritis (defined as the acute onset of watery or extremely loose stools with or without vomiting of 14 days duration or less and without infection outside the gastrointestinal tract or other illness) were entered into the study from July 1986 to February 1987.

Each infant was randomised to one of four treatment regimens. Group 1 received 24 hours of oral rehydration solution (Dextrolyte, Cow and Gate), followed by 24 hours of half strength and 24 hours of three quarter strength SMA Gold Cap (Wyeth) before continued feeding with the full 
strength formula milk. Group 2 received special formula HN25 feed (Milupa) until two days after the stools returned to normal followed-on successive days-by replacement of one, three, and then all HN25 feeds by full strength SMA Gold Cap. Group 3 continued feeding with full strength SMA Gold Cap from the time of admission, and group 4 continued feeding with Formula S (Cow and Gate) from the time of admission.

Dextrolyte is a prepacked oral rehydration solution containing sodium $35 \mathrm{mmol} / \mathrm{l}$, potassium 13.4 $\mathrm{mmol} / \mathrm{l}$, chloride $30.5 \mathrm{mmol} / \mathrm{l}$, lactate $17.7 \mathrm{mmol} / \mathrm{l}$, and glucose $200 \mathrm{mmol} / \mathrm{l}$. HN25 is a low lactose feed with a reduced fat content (table 1).

On admission details of the severity and duration of diarrhoea and of any treatment already received were noted. The degree of dehydration was assessed as absent, $2 \cdot 5-5 \%, 5-10 \%$, or $10-15 \% .{ }^{12}$ All dehydrated infants were first rehydrated with Dextrolyte or intravenous fluids before receiving their assigned feeding regimen. The infants in group 1 then received a further 24 hours oral rehydration solution as the first stage in their return to full strength feed. Baby rice was given to those infants who routinely received solids to eliminate the possibility of a variety of solids influencing results. All infants were weighed on admission and the percentage weight change noted on days two and five, and at discharge.

All intake, and stool output and quality, were noted by nursing staff. Stools were described as constipated, normal soft, curdy, loose, or watery. The duration of diarrhoea was defined as 24 hours after the last fluid stool, and the severity of diarrhoea as the number of watery or loose stools each day until the diarrhoea stopped. Failure of treatment was defined as continued or increased severity of diarrhoea with weight loss or deteriorating fluid-electrolyte imbalance, or both. These children were treated with oral rehydration solution or intravenous fluids, or both, and with a gradual reintroduction of formula milk according to the standard regimen used in this hospital. If there was a further relapse, a soya or hydrolysed casein formula milk (Formula $S$ or Nutramigen) was substituted. Stool specimens were examined for Salmonella and Shigella (desoxycholate citrate agar), Campylobacter (Skirrow's medium), Escherichia coli (MacConkey's agar), Cryptosporidia (auramine carbol fuchsin stain), and for rotaviruses (enzyme immunoassay).

The study was approved by the hospital ethical committee and fully informed verbal parental consent obtained in all cases. The significance of differences was assessed by the $\chi^{2}$ test, one way analysis of variance, contingency table analysis, and multiple regression analysis.

\section{Results}

The characteristics of the 200 babies on admission are shown in table 2 . One way analyses of variance or contingency table analysis, as appropriate, indicated no significant differences in admission characteristics among the groups. Three babies in each of groups 1 and 2, and four babies in each of groups 3 and 4 , were mildly dehydrated $(2 \cdot 5-5 \%)$. One baby in group 1 , three in group 2 , and two in group 3 were moderately dehydrated $(5-10 \%)$; All the other babies were clinically well hydrated. Only nine babies were below the third centile for weight.

One way analysis of variance showed significant differences in weight change at 48 hours among the four feeding regimens $(\mathrm{p}=0 \cdot 01)$. Group 1 babies lost weight, and groups 2,3 , and 4 gained weight, the greatest change being in babies in group 2 . These changes remained significant at five days $(p=0 \cdot 05)$

Table 1 Composition of infant feeding formulas

\begin{tabular}{|c|c|c|c|c|}
\hline & $H N 25^{*}$ & SMA Gold Cap & Formula $S$ & $\begin{array}{l}\text { DHSS guidelines } \\
\text { for nutrient } \\
\text { content } 100 \mathrm{ml}\end{array}$ \\
\hline †Main protein source $($ content/100 ml) & Cows' milk $(2.5 \mathrm{~g})$ & Cows' milk (1.5 g) & $\begin{array}{l}\text { Soya protein isolate } \\
(1.8 \mathrm{~g})\end{array}$ & $1 \cdot 2-2 \cdot 0 \mathrm{~g}$ \\
\hline Fat source $($ content $/ 100 \mathrm{ml})$ & Vegetable $(1.2 \mathrm{~g})$ & $\begin{array}{l}\text { Beef and vegetable } \\
(3.6 \mathrm{~g})\end{array}$ & Vegetable $(3.6 \mathrm{~g})$ & $2 \cdot 3-5 \cdot 0 \mathrm{~g}$ \\
\hline Carbohydrate source (content/100 ml) & $\begin{array}{l}\text { Banana, rice, } \\
\text { cornflour, malto- } \\
\text { dextrin }(9.5 \mathrm{~g})\end{array}$ & Lactose $(7 \cdot 2 \mathrm{~g})$ & Glucose syrup $(6 \cdot 7 \mathrm{~g})$ & $4.8-10.0 \mathrm{~g}$ \\
\hline Energy $\mathrm{kJ} / 100 \mathrm{ml}$ & 242.7 & $272 \cdot 0$ & $280 \cdot 3$ & $272 \cdot 0-313 \cdot 8$ \\
\hline
\end{tabular}

${ }^{*}$ Maximum recommended period as sole source of nourishment is 7 to 10 days.

†Specific information on the small amount of protein in HN25 contributed by the banana, rice, and cornflour is not available from the manufacturer. 
Table 2 Admission characteristics of study groups. Figures are given as mean (SD)

\begin{tabular}{|c|c|c|c|c|}
\hline & Group 1 & Group 2 & Group 3 & Group 4 \\
\hline Weight (kg) & $6 \cdot 2(1 \cdot 5)$ & $6.5(1.6)$ & $6.26(1 \cdot 8)$ & $6.5(1.4)$ \\
\hline Age (months) & $4 \cdot 5(2 \cdot 6)$ & $5 \cdot 5(2 \cdot 5)$ & $4.9(2.9)$ & $4.9(2.4)$ \\
\hline Duration of diarrhoea (days) & $5.0(3.6)$ & $4.9(3.7)$ & $5 \cdot 5(3 \cdot 3)$ & $4 \cdot 3(3 \cdot 3)$ \\
\hline No of diarrhoeal stools/day & $5 \cdot 7(2 \cdot 7)$ & $6.5(3.9)$ & $7 \cdot 0(4 \cdot 3)$ & $6 \cdot 7(3.7)$ \\
\hline Packed cell volume & $.037(.027)$ & $.034(.035)$ & $.034(.042)$ & $.034(.037)$ \\
\hline Plasma sodium concentration (mmol/l) & $139(2.9)$ & $139(2 \cdot 9)$ & $139(2 \cdot 7)$ & $139(4.4)$ \\
\hline Plasma potassium concentration $(\mathrm{mmol} / \mathrm{l})$ & $4 \cdot 6(0 \cdot 5)$ & $4 \cdot 6(0 \cdot 4)$ & $4 \cdot 6(0 \cdot 7)$ & $4.6(0.53)$ \\
\hline Plasma chloride concentration $(\mathrm{mmol} / \mathrm{l})$ & $105(4 \cdot 2)$ & $106(4 \cdot 0)$ & $106(4 \cdot 4)$ & $106(4 \cdot 5)$ \\
\hline Plasma bicarbonate concentration $(\mathrm{mmol} / \mathrm{l})$ & $20(3 \cdot 2)$ & $19(3 \cdot 1)$ & $19(3 \cdot 8)$ & $20(3 \cdot 1)$ \\
\hline Plasma urea concentration $(\mathrm{mmol} / \mathrm{l})$ & $3 \cdot 2(2 \cdot 1)$ & $3.4(1 \cdot 8)$ & $3 \cdot 5(2 \cdot 5)$ & $3.7(3.9)$ \\
\hline Plasma creatinine concentration $(\mu \mathrm{mol} / \mathrm{l})$ & $37(9 \cdot 8)$ & $40(15)$ & $41(18 \cdot 7)$ & $38(14 \cdot 8)$ \\
\hline $\begin{array}{l}\text { Treatment with oral rehydration solution } \\
\text { before admission }\end{array}$ & 32 of 50 & 29 of 50 & 27 of 50 & 29 of 50 \\
\hline
\end{tabular}

There were no significant differences.

but had virtually disappeared by the time of discharge when the differences were no longer significant (figure).

The factors affecting the weight gain after two days in hospital were further examined by a multiple regression analysis of the gain on the admission variables and on the feeding regimen. The coefficient for the effect of intravenous rehydration is significant $(p=0.05)$ and this implies that intravenous rehydration results in weight gains of up to $2 \%$ more when compared with those not requiring intravenous fluids. One baby in group 1 received intravenous fluid replacement for 38 hours after admission, three babies in group 2 for 25,26 , and 40 hours, respectively, two babies in group 3 for 21 and 68 hours, respectively, and two babies in group 4 for 38 and 60 hours, respectively. These differences are not significant. A mean period of 12 hours (range four to 24) was taken for oral rehydration with Dextrolyte.

Differences between the groups in the severity of diarrhoea after admission were significant $(p=0 \cdot 05)$ being less in group 2 (mean (SD) $0.8(1.7)$ diarrhoeal stools a day) than in group $3(1.8(1.5)$ a day), with group $4(1.4(1.9)$ and group $1(1.6(1.7))$ occupying intermediate positions. There was no significant difference among the four treatment groups in the duration of diarrhoea after admission, the mean (SD) times being 64 (53.7), 47 (53.7), 68 $(43 \cdot 6)$, and $51(41.5)$ hours, respectively, nor in the times to discharge, which were $6.9(3.2), 6.9(1.9)$, $6 \cdot 9(2 \cdot 2)$, and $7 \cdot 1(3 \cdot 6)$ days, respectively. Details of the gut pathogens identified in the infants' stools are shown in table 3 .

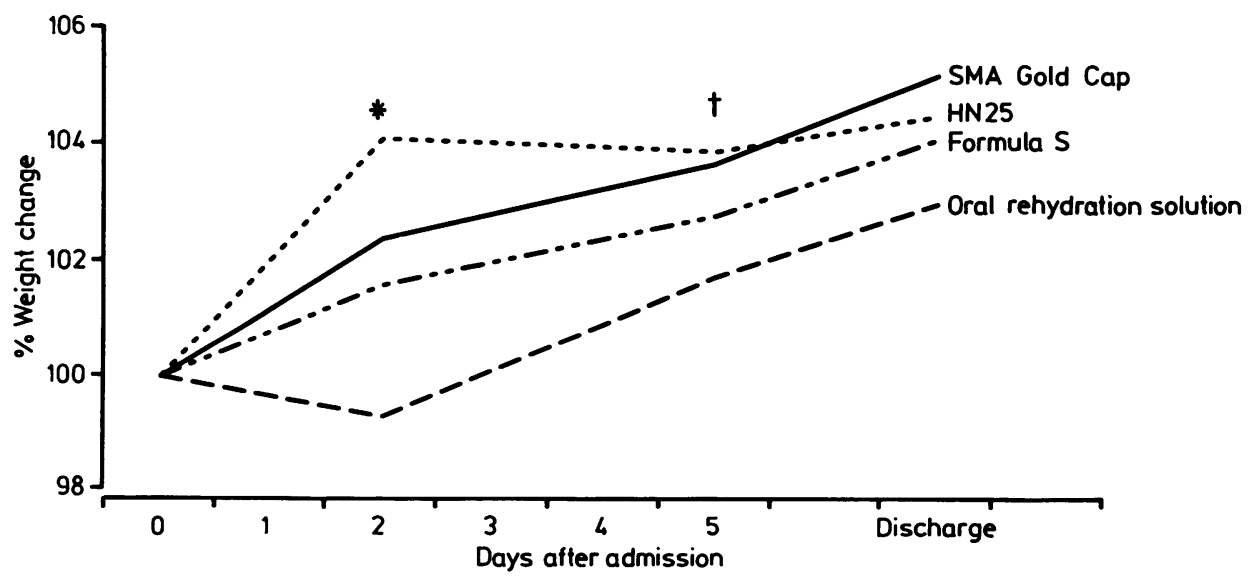

Figure Percentage weight change at day $2\left({ }^{*} p=0 \cdot 01\right)$, day $5(\dagger p=0.05)$, and discharge (NS). 
Table 3 Results of stool examination for gut pathogens

\begin{tabular}{|c|c|c|c|c|}
\hline & Group & 1 Group & 2 Group & 3 Group 4 \\
\hline No agent identified & 34 & 37 & 30 & 28 \\
\hline Rotavirus & 12 & 9 & 11 & 13 \\
\hline Salmonella spp & 3 & 1 & 3 & 6 \\
\hline Campylobacter & 0 & 1 & 1 & 2 \\
\hline Escherichia coli & 0 & 2 & 4 & 1 \\
\hline Rotavirus and $E$ coli & 1 & 0 & 0 & $\mathbf{0}$ \\
\hline $\begin{array}{l}\text { Rotavirus, Salmonella } \\
\text { spp, and } E \text { coli }\end{array}$ & 0 & 0 & 1 & 0 \\
\hline Total & 50 & 50 & 50 & 50 \\
\hline
\end{tabular}

Two babies in group 1 (one who had rotavirus and one in whom no pathogen was identified), eight babies in group 2 (one who had Salmonella sp, one who had rotavirus, and six in whom no pathogen was identified), four babies in group three (one who had Salmonella species, two who had rotavirus, and one in whom no pathogen was identified), and four babies in group 4 (one who had Salmonella sp, one who had $E$ Coli, and two in whom no pathogen was identified), were designated failures of treatment. There is no evidence that the probability of failure of treatment differed among the groups. It may be concluded that the observed differences are random effects.

One of the two failures in group 1 settled with a second standard return to normal feeding, the other on Formula S. Of the eight failures in group 2 six tolerated the HN25 well and relapsed only on the introduction of SMA Gold Cap. All of these failed a second return to normal feeding but settled when given Formula $\mathbf{S}$ or Nutramigen. One baby in group 2 was withdrawn from the trial because of early vomiting. This continued when he was given Dextrolyte, and in retrospect was probably a relection of his rotavirus infection. The remaining failure in group 2 was withdrawn because of continued diarrhoea and weight loss (200 $\mathrm{g}$ in five days). Salmonella Worthington was isolated from the stools. Moderate diarrhoea continued during return to normal feeding, the child being discharged thriving but with persistent watery stools at 10 days. Three failures in group 3 settled the second time a return to normal feeding was attempted, and one required Nutramigen. Three failures in group 4 continued with profuse diarrhoea despite oral rehydration solution, and required intravenous fluid replacement. One failure in group 4 with a history of atopy settled only when given Nutramigen. Allergy to cows' milk or soya were presumed to account for most of the failures of treatment. In our opinion no baby had persistent diarrheoa severe enough to warrant a small bowel biopsy. Only three failures of treatment required intravenous fluids $(4 \%$ dextrose and $0 \cdot 18 \%$ sodium chloride) for 32,38 , and 44 hours, respectively. Three, 10, and three stools, respectively were passed during the period of intravenous treatment and on discontinuation of this the infants were tolerating full strength feeds within 33,80 , and 28 hours without any subsequent relapse.

These 18 babies did not differ significantly from those successfully treated in weight or age at admission, in duration or severity of diarrhoea, in packed cell volume, or plasma sodium, potassium, chloride, bicarbonate, urea or creatinine concentrations. None of the babies was dehydrated on admission.

One hundred and seventeen babies received treatment with an oral rehydration solution before admission. Four of the 18 failures of treatment occurred in this group and 14 in the 83 babies who had received no oral rehydration solution. Contingency table analysis indicated significant differences in these proportions of failures $(p=0 \cdot 001)$.

\section{Discussion}

The continuation of breast feeding is routinely recommended in breast fed infants with acute gastroenteritis ${ }^{3}$ and has been shown to be of clinical benefit when compared with the use of oral rehydration solution alone. ${ }^{13}$ It is illogical to advocate continued breast feeding on the one hand, and a period of fasting and diluted cows' milk formula for non-breast fed infants on the other. Recent studies have substantiated the early work of Chung in confirming the safety and benefits of early refeeding in acute gastroenteritis of childhood. ${ }^{14}{ }^{15}$ Reservations have been expressed concerning rapid refeeding in early infancy ${ }^{15} 16$ although delayed recovery seems to be restricted to infants who are both young and malnourished. ${ }^{11} 17$

It is probably essential for an infant to be well hydrated for rapid refeeding to be successful, so that the dangers of prolonged acidosis and protracted vomiting are avoided. ${ }^{8}$ We have shown that well nourished, well hydrated infants, most with acute mild gastroenteritis, have no need for a gradual return to normal feeding. Those infants allocated to a rapid refeeding regimen showed better early weight gain with no increase in the duration of diarrhoea or in the time spent in hospital. All four feeding regimens were well tolerated. There were no long term complications in any of the 18 infants who failed to respond to treatment.

In northern Europe there is widespread acknowledgment of the decreasing incidence of lactose intolerance,${ }^{11} 16$ which is probably largely a secondary manifestation of cows' milk protein 
intolerance. ${ }^{19}$ The results of a study of a nonhospital based, less selected population suggest that there is no need for routine use of a non-lactose formula in the treatment of mild acute gastroenteritis. ${ }^{20}$ Moreover, documented lactose intolerance invariably responds rapidly to temporary omission of lactose from the diet. ${ }^{21}$ Our results show better early weight gain in group 2 (HN25), and less severe diarrhoea in groups 2 (HN25) and 4 (Formula $\mathrm{S})$, but no difference in either the duration of diarrhoea or in time to discharge when compared with group 3 (SMA Gold Cap). Modern adapted low solute cows' milk formula feeds are at least as effective as a hypoallergenic feeding formula (Pregestimil) in preventing sensitisation of the gut. ${ }^{11}$ Our study confirms the safety of rapid refeeding with a standard formula feed.

One hundred and seventeen of our 200 infants had received oral rehydration solution before admission, and thus it is not possible to extrapolate from our results to discussion of the safety and benefits of continued feeding, as opposed to rapid refeeding, in acute infantile diarrhoea. It is significant $(p=0.001)$ that 14 of the 18 failures of treatment had not received treatment with an oral rehydration solution before admission. This may be attributed to the beneficial effects of the early treatment or alternatively could imply that general practitioners are themselves less likely to treat cases where the expectation of success is judged to be low. None the less, $53(82 \%)$ of 65 babies who received no oral rehydration solution before admission and who were subsequently allocated to groups 2,3 , or 4 settled well on a continued feeding regimen. A cautious interpretation of our results, however, necessitates a 24 hour period of treatment with an oral rehydration solution before the resumption of full milk feeds.

Patients who fail to respond to this regimen may be given a further 24 hour period of oral rehydration solution followed by a standard return to normal feeding or rapid feeding with either a soya based or hydrolysed casein formula milk. Whenever a special formula milk is used, return to normal feeding should be supervised. Infants with acute gastroenteritis without signs of clinical dehydration, or after rehydration with an oral rehydration solution or intravenous fluids, need have little disturbance in their normal dietary intake. Full milk feeding may be resumed immediately with a rapid reintroduction of solids where indicated.

We thank Dr J Stevenson and Dr H Pullen for permission to study their patients and for encouragement and advice, Dr A Baines for the statistical analysis, and the nursing staff for their support.

\section{References}

${ }^{1}$ Pullan CR, Dellagrammatikas H, Steiner H. Survey of gastroenteritis in children admitted to hospital in Newcastle upon Tyne in 1971-5. Br Med J 1977;i:619-21.

2 Isaacs D, Day D, Crook S. Childhood gastroenteritis: a population study. Br Med J 1986;293:545-6.

3 Brown KH, MacLean WC. Nutritional management of acute diarrhoea: an appraisal of the alternatives. Pediatrics 1984;73:119-25.

${ }^{4}$ Chung AW. The effect of oral feeding at different levels on the absorption of foodstuffs in infantile diarrhoea. $J$ Pediatr 1948;33:1-13.

${ }^{5}$ Chung AW, Viscorova B. The effect of early oral feeding versus early oral starvation on the course of infantile diarrhoea. $J$ Pediatr 1948;33:14-22.

6 Soeprapto, Soenarto Y, Nelwan, Meoenginah PA, Ismangoen. Feeding children with diarrhoea. Trop Pediatr Environ Child Health 1979;25:97-100.

7 Knudsen KB, Bradley EM, Lecocq FR, Bellamy HM, Welsh J. Effect of fasting and refeeding on the histology and disaccharidase activity of the human intestine. Gastroenterology 1968;55:46-51.

8 Wharton BA. Gastroenteritis in Britain: management at home. Br Med J 1981;283:1277-8.

9 Wharton BA, Pugh RE, Taitz LS, Walker-Smith JA, Booth IW. Dietary management of gastroenteritis in Britain. $\mathrm{Br}$ Med J 1988;296:450-2.

10 Anonymous. What has happened to carbohydrate intolerance following gastroenteritis? Lancet 1987;i:23-4.

11 Manuel PD, Walker-Smith JA. A comparison of three infant feeding formulae for the prevention of delayed recovery after infantile gastroenteritis. Acta Pediatrica Belgia 1981;34:13-20.

12 Ironside AG, Tuxford AF, Heyworth B. A survey of infantile gastroenteritis. $\mathrm{Br}$ Med $J$ 1970; iii: $20-4$.

13 Khin-Maung-U, Nyunt-Nyunt-Wai, Myo-Khin, Mu-Mu-Khin, Tin-U, Thane-Toe. Effect on clinical outcome of breast feeding during acute diarrhoea. Br Med J 1985;290:587-9.

14 Rees L, Brook CGD. Gradual reintroduction of full strength milk after acute gastroenteritis in children. Lancet 1979;i:770-1.

15 Dugdale A, Lovell S, Cribbs V, Ball D. Refeeding after acute gastroenteritis: a controlled study. Arch Dis Child 1982;57:76-8.

16 Isolauri E, Vesikari T, Saha P, Viander M. Milk versus no milk in rapid refeeding after acute gastroenteritis. J Pediatr Gastroenterol Nutr 1986;5:254-61.

17 Placzek M, Walker-Smith JA. Comparison of two feeding regimens following acute gastroenteritis in infancy. $J$ Pediatr Gastroenterol Nutr 1984;3:245-8.

18 Isolauri E, Vesikari T. Oral rehydration, rapid feeding, and cholestyramine for treatment of acute diarrhoea. $J$ Pediatr Gastroenterol Nutr 1985;4:366-74.

19 Walker-Smith JA. Cow's milk intolerance as a cause of postenteritis diarrhoea. J Pediatr Gastroenteral Nutr 1982;1:16373.

20 Groothuis JR, Berman S, Chapman J. Effect of carbohydrate ingested on outcome in infants with mild gastroenteritis. $J$ Pediatr 1986;108:903-6.

21 Davidson GP, Goodwin D, Robb TA. Incidence and duration of lactose malabsorption in children hospitalised with acute enteritis: a study in a well nourished urban population. $J$ Pediatr 1984;105:587-90.

Correspondence to Dr SP Conway, Department of Infectious Disease, Seacroft Hospital, York Road, Leeds, LS14 6UH.

Accepted 9 August 1988 